\title{
Selectivity and Mechanism of Thermal Decomposition of $\beta$-diketones on ZnO Powder
}

\author{
Hsuan Kung and Andrew Teplyakov* \\ University of Delaware, Department of Chemistry and Biochemistry, \\ Newark, DE 19716
}

\begin{abstract}
The thermal chemistry of $\beta$-diketones underlies a number of catalytic processes related both to the catalytic reactions yielding commodity chemicals and to the production of supported transition metal catalysts themselves. The mechanisms of decomposition during thermal transformation of three $\beta$-diketones, acetylacetone (acacH), 1,1,1-trifluoroacetylacetone $(\mathrm{tfacH})$, and 1,1,1,5,5,5-hexafluoroacetylacetone (hfacH), were studied on $\mathrm{ZnO}$ powder surface using Fourier-transform infrared spectroscopy (FT-IR), X-ray photoelectron spectroscopy (XPS), and Density functional theory (DFT) computational investigation. The initial $\mathrm{O}-\mathrm{H}$ dissociation leads to the formation of corresponding $\beta$-diketonates in all the cases investigated. These diketonates are important surface intermediates that can be generated in a controlled manner in these experiments. The presence on the $\mathrm{C}-\mathrm{CF}_{3}$ entity determines the preferred thermal decomposition pathways, as the $\mathrm{C}-\mathrm{C}$ bond in this group starts to react with a surface of $\mathrm{ZnO}$ around 400 $\mathrm{K}$, followed by immediate decomposition of the resulting $\mathrm{CF}_{3}$ group. Above $600 \mathrm{~K}$, the presence of the $\mathrm{CF}_{3}$-substituent leads to the formation of ketene-like structures observed by vibrational spectroscopy. The reaction mechanisms examined with the help of DFT calculations are correlated with vibrational signatures of the species produced and with the F-containing species recorded by XPS.
\end{abstract}

* Corresponding author: Department of Chemistry and Biochemistry, University of Delaware, Newark, DE 19716. Tel.: (302) 831-1969; Fax: (302) 831-6335; e-mail: andrewt@udel.edu 


\section{Introduction}

Thermal chemistry of $\beta$-diketones plays a number of important roles in catalysis, microelectronics, and sensing [1-4]. This class of compounds is interesting from a chemical point of view because of a rich chemistry related to the presence of two different tautomeric forms in liquid or gas phases with concentrations depending upon a specific compound [5, 6]. Figure 1 shows tautomeric forms of three common $\beta$-diketonatones: acetylacetone $(\mathrm{acacH}), \quad$ trifluoroacetylacetone $(\mathrm{tfacH})$ and hexafluoroacetylacetone (hfacH).

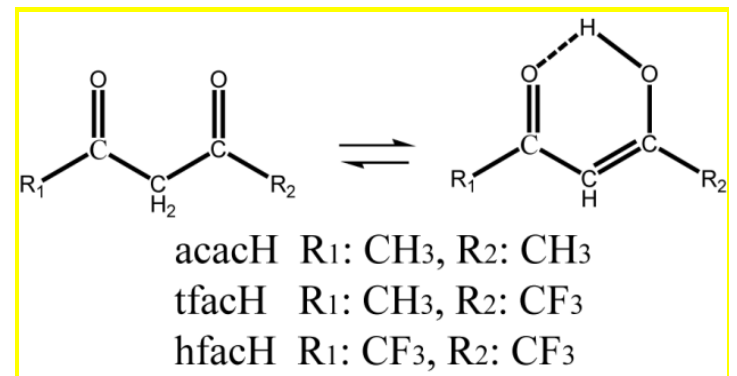

Figure 1. Three common $\beta$-diketones: acetylacetone (acacH), 1,1,1- trifluoroacetylacetone $(\mathrm{tfacH})$ and 1,1,1,5,5,5-hexafluoroacetylacetone $(\mathrm{hfacH})$.

This structure implies that a complex interplay and synergistic interaction of multiple functional groups determines the thermal chemistry of these compounds on surfaces. In the case of catalytic transformation, these compounds can serve as test models for analyzing the intramolecular interaction of $\mathrm{O}-\mathrm{H}, \mathrm{C}=\mathrm{O}, \mathrm{C}=\mathrm{C}$, and $\mathrm{C}-\mathrm{CF}_{3}$ functionalities in determining the reactivity of current and potential catalytic systems that 
are used for commodity chemicals. In addition to this direct involvement in catalysis, $\beta$-diketonates and their hydrogenated forms are extremely important in understanding the production of transition metal catalysts supported on oxides by means of chemical vapor deposition. Specifically, nanoparticulate catalysts can be deposited with great precision by chemical vapor deposition, and $\beta$-diketonates serve as perfect ligands to depositing such metals as $\mathrm{Ni}, \mathrm{Co}, \mathrm{Cu}, \mathrm{Pt}$ and many more $[7,8]$. In addition, $\beta$-diketonate ligands are commonly utilized in either $\mathrm{Cu}(\mathrm{I})$ or $\mathrm{Cu}(\mathrm{II})$ precursors that allow for controlling the oxidation state of a deposited metal. ( $\beta$-diketonate $) \mathrm{Cu}(\mathrm{I}) \mathrm{L}$ ( $\mathrm{L}=$ olefin or alkyne) or ( $\beta$-diketonate) ${ }_{2} \mathrm{Cu}(\mathrm{II})$ exhibit substantial differences in phase (solid vs. liquid), vapor pressure and decomposition and dissociation temperatures [8]. Therefore, it is imperative to understand the chemical transformations of these compounds and the driving forces behind them on common support materials, such as, for example, $\mathrm{ZnO}$ powder. In fact, the choice of $\mathrm{ZnO}$ is based on much more than its use as a mere support material. With its unique physical and chemical properties, $\mathrm{ZnO}$ has been gaining interest as a heterogeneous catalyst for various organic reactions such as hydrogenation, acylation condensation and oxidation [9-11]. In addition, it is also a prospective environmentally friendly photocatalyst for mineralization of organohalogen pollutants [12-14]. All these applications reveal the catalytic reactivity of $\mathrm{ZnO}$ with respect to carbon-carbon, 
carbon-hydrogen, carbon-oxygen, and carbon-halogen bonds. With these specific interactions in mind, $\mathrm{ZnO}$ will be the target of this study involving several structurally similar fluorinated diketones.

Because of their applications in microelectronics, a number of studies of metal $\beta$-diketonates have been reported on materials such as titanium nitride, copper, and silicon [15-17]. Several reports also explicitly target chemical vapor deposition (CVD) and atomic layer deposition (ALD) of transition metal catalysts on oxide materials [18-20], where decomposition reactions of $\beta$-diketonates are complex and can cause carbon, oxygen or fluorine contamination on the surface at elevated temperatures.

Understanding chemistry of $\beta$-diketones and $\beta$-diketonates on $\mathrm{ZnO}$ powder, with all the complexity of potential surface processes, may seem to be extremely challenging; however, as will be shown below, this approach is actually simplified by the fact that the starting step in enol reactions for the majority of surface processes involving $\beta$-diketones is $\mathrm{O}-\mathrm{H}$ dissociation. Thus, a surface diketonate is formed initially, and the process of thermal decomposition can be further studied to understand surface chemistry for both $\beta$-diketones and for $\beta$-diketonate species.

The non-polar mixed-terminated $\mathrm{ZnO}(10 \overline{1} 0)$ surface comprises approximately $80 \%$ of the exposed surfaces in $\mathrm{ZnO}$ powder, with approximately $10 \%$ corresponding to a 
polar $\mathrm{Zn}$-terminated $\mathrm{ZnO}(0001)$ and another $10 \%$ to O-terminated $\mathrm{ZnO}(000 \overline{1})$ faces [21]. The terraces of the O-terminated $\mathrm{ZnO}(000 \overline{1})$ surface [22] have been shown to be unreactive to $\mathrm{O}-\mathrm{H}$ dissociation and the reactive defect sites comprise only a few percent [23]. Thus, most of the experimental studies of powder $\mathrm{ZnO}$ materials follow the actual reactions on $\mathrm{ZnO}(10 \overline{1} 0)$ surface, and the minority species are from the $\mathrm{Zn}$-terminated $\mathrm{ZnO}(0001)$ surface. Therefore, the computational studies reported below will focus on the $\mathrm{ZnO}(10 \overline{1} 0)$ surface.

In this work, the main goal is to understand the role of the $\mathrm{C}_{-} \mathrm{CF}_{3}$ functionality in determining the pathways and mechanisms for thermal decomposition of $\beta$-diketones on $\mathrm{ZnO}$. $\mathrm{ZnO}$ powder is exposed to three different $\beta$-diketone compounds. The initial adsorption is shown to yield surface $\beta$-diketonates. $\mathrm{ZnO}$ surface is then annealed to different temperatures and chemical transformations are followed with Fourier-transform infrared spectroscopy (FT-IR) and X-ray photoelectron spectroscopy (XPS) to determine surface chemical groups present as a function of temperature. The possible thermal transformations of adsorbed structures and their relative thermal stability are investigated using density functional theory (DFT) calculations. This approach is important in understanding the governing principles determining the thermal stability of surface $\beta$-diketonates and the role that their chemical structure plays in mechanisms of surface 
decomposition. This general understanding will lead to preventing the surface decomposition pathways that can poison the produced catalyst and provide the foundation for reaction designs for several commodity chemicals.

\section{Experimental}

\subsection{Powder sample preparation and FT-IR characterization}

All $\mathrm{ZnO}$ powder samples were prepared as described earlier [20]. A sample of approximately $30 \mathrm{mg}$ of $\mathrm{ZnO}$ powder (99.99\% purity, Alfa Aesar) was pressed onto a tungsten mesh under a pressure of $\sim 4$ tons using a hydraulic press. This assembly was mounted onto copper leads used for resistive heating and a k-type thermocouple was spot-welded directly to the mesh to monitor the temperature. The samples were then loaded into a custom-made infrared chamber [24] and pumped down to $1 \times 10^{-6}$ Torr. $\mathrm{ZnO}$ samples were initially annealed to $850 \mathrm{~K}$ to remove surface contamination and the dosing of appropriate compounds was performed at room temperature following this preparation step. As was shown previously, this procedure minimizes the number of surface defects and impurities on $\mathrm{ZnO}$ powder surface [25]. Three common $\beta$-diketone compounds: acetylacetone $(\mathrm{acacH})(99+\%$, Fisher Scientific), 1,1,1-trifluoro-acetylacetone (tfacH) (98\%, Alfa Aesar), and 1,1,1,5,5,5-hexafluoro-2,4-pentanedione (hfacH) (98+\%, Alfa 
Aesar) were used in this study. Compounds were first treated with freeze-pump-thaw cycles and then dosed into the chamber via a leak valve. The dosing pressure was 1 Torr, and a dosing time of 2 minutes was used to lead to full saturation of the surface as confirmed by exposure profile. The prepared sample was then annealed to the desired temperatures and cooled down to room temperature for transmission infrared spectroscopy investigations. The purity of the compounds was verified by a mass spectrometry (SRS mass spectrometer) performed in a different ultra-high vacuum chamber and then confirmed in situ by collecting infrared spectra in the gas phase at 1 Torr.

FT-IR experiments were performed using a Nicolet Magna 560 spectrometer with a nitrogen-cooled MCT detector to collect the infrared spectra in a transmission mode. The entire optical path of the infrared beam was purged by water- and $\mathrm{CO}_{2}$-free air. All spectra were collected with a resolution of $4.0 \mathrm{~cm}^{-1}$ and 512 scans per spectrum. An ion gauge was used for low pressure measurements in high-vacuum and a Baratron gauge (MKS Instruments) for high pressure exposures. All quantitative analysis of infrared spectra was performed using Origin 9.1 software. 


\subsection{X-ray photoelectron spectroscopy (XPS).}

Two different XPS instruments were utilized in this study to investigate adsorption and thermal decomposition of tfacH and hfacH on $\mathrm{ZnO}$ powder samples, focusing mostly on the F $1 s$ spectral region. These two instruments yield very different absolute intensity of the recorded signals. However, in both cases the signal-to-noise ratios are very high and the resolution is set to be identical. The features observed in the F 1s spectral region for tfacH and hfacH studies are separated by several electron-volts and thus the analyses performed are independent of the XPS instrument used. The studies of tfacH reactions were performed at a PHI-5600 electron spectrometer equipped with a monochromatic aluminum $\mathrm{K} \alpha(1486.6 \mathrm{eV}) \mathrm{X}$-ray source. The $\mathrm{hfacH}$ samples were studied on a VG Scientific 220i-XL electron spectrometer instrument with the same X-ray source. For both instruments, a pass energy of $58.7 \mathrm{eV}$ was used to collect all spectra with $0.25 \mathrm{ev} / \mathrm{step}$ resolution. All peak positions were calibrated by $\mathrm{C} 1 \mathrm{~s}$ peak at $284.6 \mathrm{eV}$ using CasaXPS software.

\subsection{Computational methods}

All the DFT calculations were performed using B3LYP functional [26-28] and LANL2DZ basis set [29-31] as implemented in the Gaussian 09 suite of programs [32]. 
This approach has been successfully used earlier to obtain energy landscapes and spectroscopic observables based on cluster calculations [20, 25, 33-35]. As mentioned above, the majority of $\mathrm{ZnO}$ powder surface is $\mathrm{ZnO}(10 \overline{1} 0)$, and in these studies it is represented by a $\mathrm{Zn}_{20} \mathrm{O}_{20}$ cluster model. The key atoms representing the topmost layer of the material and the adsorbed species were allowed to move freely during the optimization procedure, the rest of the atoms in the cluster models were fixed at their bulk positions to prevent unrealistic distortion. This relatively large cluster allows for a description of four surface $\mathrm{Zn}-\mathrm{O}$ dimers simultaneously. Energies of each optimized model were calculated to obtain relative energies $(\Delta \mathrm{E})$ for comparison. The predicted infrared spectra of the organic surface fragments were calculated to compare with experimental results. Based on the previous successful investigations, a scaling factor of 0.97 was used to account for systematic errors and to compare experimental and computationally-predicted infrared spectra. Transition states were determined using synchronous transit-guided quasi-newton (STQN) $[36,37]$ method and confirmed by the presence of a single negative eigenvector (a negative frequency) in the corresponding frequency calculations. XPS measurements were compared with computationally predicted spectra using a calibration procedure described in detail previously [38]. 


\section{Results and Discussion}

\subsection{Thermal stability of acacH, tfacH and hfacH on $\mathrm{ZnO}$ powder determined by FTIR}

The room-temperature adsorption of acacH and $\mathrm{hfacH}$ on $\mathrm{ZnO}$ powder surface has been investigated previously by FT-IR [34, 39]. Adsorption of both these diketones primarily leads to $\mathrm{O}-\mathrm{H}$ dissociation and formation of corresponding $\beta$-diketonates. tfacH on $\mathrm{ZnO}$ surface is expected to exhibit similar behavior at room temperature. This section compares the adsorption of the three diketones and follows their thermal chemistry after brief annealing to the desired temperature.

\subsubsection{Thermal transformation of adsorbed acacH}

As will be demonstrated below, thermal chemistry of acacH is very different from that of the other two diketonates studies here. Thus, a separate section is dedicated to this compound adsorbed on $\mathrm{ZnO}$ powder. As summarized in Figure 2, $\mathrm{C}=\mathrm{C} / \mathrm{C}=\mathrm{O}$ combination stretch and $\mathrm{CH}_{3}$ stretches are clearly observed for this compound at room temperature.

The complete assignment can be made based on the computational investigation of a cluster model presented schematically in Figure $2 \mathrm{a}$ and is presented in Table $\mathrm{S} 1$ in

Supporting Information section. This assignment is fully consistent with the formation of surface-bound acac diketonate following $\mathrm{O}-\mathrm{H}$ dissociation in acacH at room temperature on $\mathrm{ZnO}$ powder. According to the recorded temperature profile, no substantial changes 
are observed in the vibrational spectra until about $600 \mathrm{~K}$, where the intensity of the absorption bands drops drastically and they nearly completely disappear by $700 \mathrm{~K}$. This observation indicates that the majority of acac ligands on the $\mathrm{ZnO}$ surface remain intact up until the surface temperature reaches $600 \mathrm{~K}$. At this point, the majority of surface-bound hydrocarbon fragments are desorbed or decomposed. The same conclusion can be reached based on the entire spectral region investigated, since the intensity of all the observed vibrational bands decreases simultaneously.

It is important to note that for acacH no additional peaks are observed within the $1900-2100 \mathrm{~cm}^{-1}$ spectral region, where vibrational signatures of ketene-like surface structures could appear. This study does not aim at full understanding of surface transformation of acacH; however, it does confirm that the acac species formed on the $\mathrm{ZnO}$ powder surface following acacH adsorption remain intact up until approximately $600 \mathrm{~K}$.

One additional piece of information could potentially be obtained following examination of the $\mathrm{O}-\mathrm{H}$ stretching region, since the formation of surface diketonates is expected to produce a single surface bound hydroxyl group. The previous vibrational investigation of the $\mathrm{O}-\mathrm{H}$ absorptions in infrared region for water adsorbed on $\mathrm{ZnO}$ nanoparticle [40] could help this assignment. Unfortunately, hydroxyl groups are rather 
difficult to analyze by infrared spectroscopy for more complex reactions. As has been demonstrated previously for ethanol dissociation on $\mathrm{ZnO}$ powder [25], the frequency of the hydroxyl group produced by such a dissociation is extremely sensitive to the neighboring species and this interaction can potentially shift this frequency all the way into the $\mathrm{C}-\mathrm{H}$ stretching spectral region, similarly to the "softening" effect reported on metal surfaces [41]. Thus, together with inhomogeneous broadening, this would result in nearly uninterpretable vibrational signatures. A summary of the $\mathrm{O}-\mathrm{H}$ stretching spectral regions recorded for $\mathrm{acacH}$, hfacH, and tfacH adsorbed on $\mathrm{ZnO}$ powder at room temperature is provided in Figure S1 of the Supporting Information section, and these spectra are compared with the spectrum of the same powder material exposed to water vapor, where corresponding $\mathrm{O}-\mathrm{H}$ vibrational frequencies are clearly visible.

\subsubsection{Thermal transformations of adsorbed hfac and tfac structures}

Figure 2 also compares key vibrational signatures for temperature-dependent studies of tfacH and hfacH. Both compounds exhibit strong absorption bands within the $1100-1350 \mathrm{~cm}^{-1}$ spectral region. According to the previous studies [34] and consistent with the current assignments based on the computational investigation of the corresponding cluster structures shown in Figure 2, these absorption bands correspond to a combination of $\mathrm{C}-\mathrm{F}$ stretches and $\mathrm{C}-\mathrm{H}$ bending vibrations, thus confirming the presence 
of $\mathrm{CF}_{3}$ groups in the adsorbed species. A full list of assignments based on this computational investigation is provided in Table S1 of the Supporting Information section. A peak around $1250 \mathrm{~cm}^{-1}$ (one of important signatures of $-\mathrm{CF}_{3}$ ) for both hfac and tfac diminishes as a function of temperature, likely suggesting a change in the chemical environment of corresponding $\mathrm{CF}_{3}$ groups and possibly correlating with their reaction with a surface, as will be discussed in more detail further. This change is observed at temperature much lower than that required to start decomposition of acacH described in section 3.1.1 above. Additionally, except for the changes in this single absorption feature with temperature, the rest of the bands remain largely unaffected, even following annealing to $700 \mathrm{~K}$, which is already very different from the observations of acacH behavior described in the previous section. At temperatures above $700 \mathrm{~K}$, new absorption features appear at $2084 \mathrm{~cm}^{-1}$ and $1992 \mathrm{~cm}^{-1}$ for hfacH and $2080 \mathrm{~cm}^{-1}$ and $1990 \mathrm{~cm}^{-1}$ for $\mathrm{tfacH}$. Adsorption of $\mathrm{CO}$ can be ruled out as a source of these features, as $\mathrm{CO}$ is known to desorb from $\mathrm{ZnO}$ at much lower temperatures [42]. Another explanation to this observation could be derived based on the formation of ketene-like species previously observed for hfacH on copper surfaces [16]. Since no peaks within this spectral region have been observed for acacH, the appearance of these features at elevated temperatures must be related to the presence and decomposition of $\mathrm{C}-\mathrm{CF}_{3}$ functionality in $\mathrm{tfacH}$ and 
hfacH. Two additional observations have to be reported: (1) $2084 \mathrm{~cm}^{-1}$ appears at lower temperatures compared to that for the $1992 \mathrm{~cm}^{-1}$ feature, and (2) hfac forms ketene-like structures at a slightly lower temperature than tfac. 

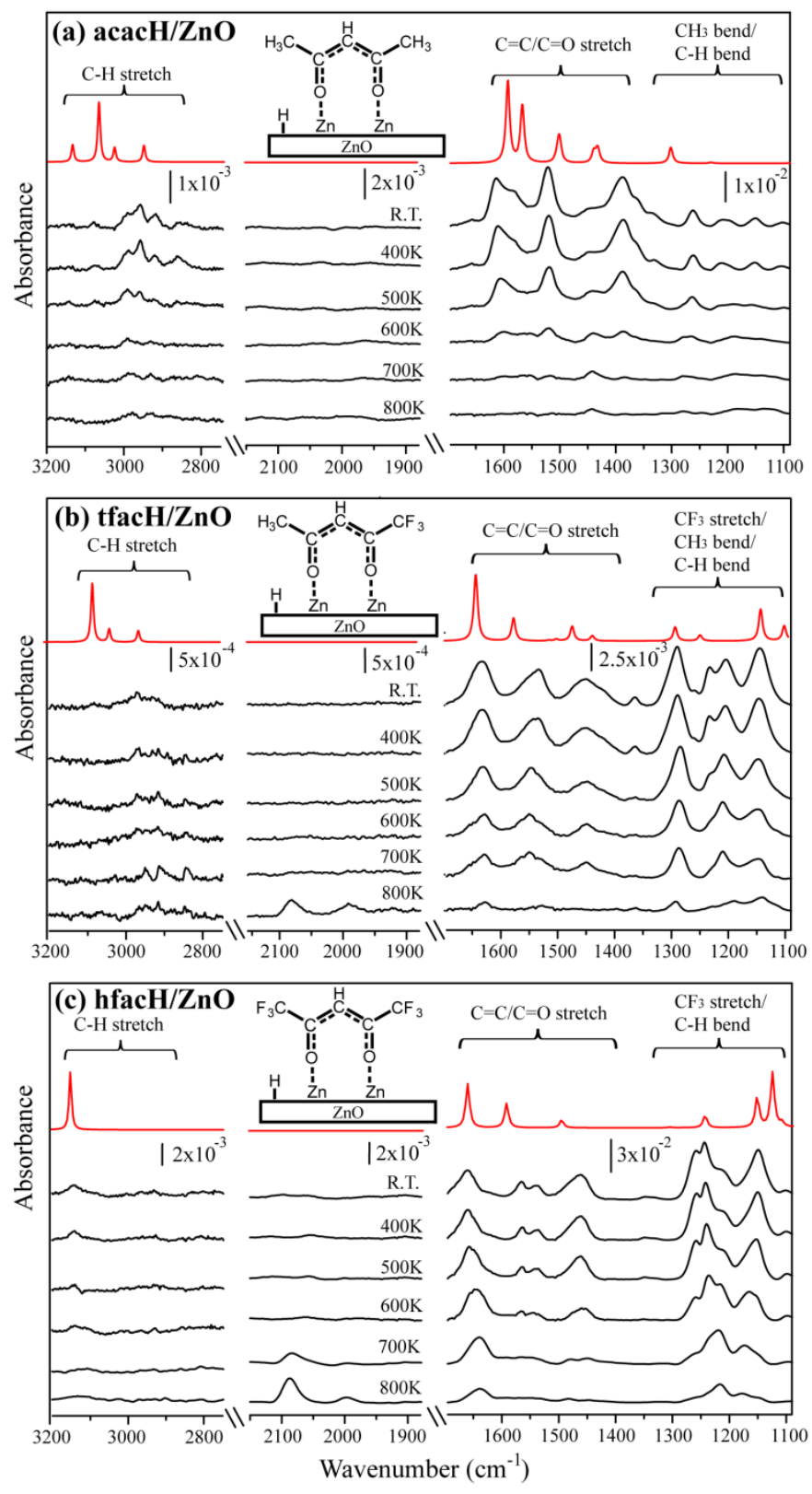

Figure 2. Temperature-dependent IR spectra of representative spectral regions for (a) acacH (b) tfacH (c) hfacH following their adsorption on $\mathrm{ZnO}$ powder surface. The computationally predicted infrared spectra of corresponding cluster models for diketonates on $\mathrm{ZnO}(10 \overline{1} 0)$ surface (as shown schematically on the right) are given in red. In the computationally predicted spectra, $\mathrm{C}-\mathrm{H}$ stretching region is corrected by a scaling factor 0.97 for visualization purposes. 


\subsection{Proposed thermal transformation mechanisms for tfac and hfac on $\mathrm{ZnO}$.}

Some of the observations summarized in Figure 2 can be understood with the help of DFT investigations that can 1) Evaluate the possible mechanistic pathways of thermal decomposition for $\beta$-diketonates starting with the reaction of the $\mathrm{C}-\mathrm{CF}_{3}$ entity; 2) Explain the formation of ketene-like structures for tfacH and hfacH at elevated temperature; 3) Provide a set of spectroscopic observables for key intermediate species to be compared with the experimental results.

Proposed thermal decomposition mechanisms for hfacH and tfacH are summarized in Figure 3. The initial step in both cases (as well as for acacH provided in Figure S2 of the Supporting Information section) is O-H dissociation of the more stable enolic form of diketones leading to the formation of surface diketonates. This step was described in detail previously for acacH and hfacH [34] and despite subtle differences in possible surface diketonates, the most stable surface structures produced are very similar for all of the $\beta$-diketones studied.

Before proceeding to evaluate the possible mechanisms for surface decomposition

of hfac and tfac, it is important to consider if the formation of surface-bound fluorine (analyzed later by XPS) could be a result of a direct abstraction of fluorine by the surface atoms versus surface decomposition following initial $\mathrm{C}_{-} \mathrm{CF}_{3}$ bond dissociation. 
Thermodynamically, the C-F bond strength $(513.8 \pm 10.0 \mathrm{~kJ} / \mathrm{mol})$ is much higher than that for the $\mathrm{C}_{-} \mathrm{CF}_{3}$ bond [43]. The addition of strongly electron-withdrawing fluorine to a $\mathrm{CF}_{3}$ group in hfacH and tfacH is expected to decrease the strength of an adjacent $\mathrm{C}-\mathrm{C}$ bond even further. An additional argument against a direct C-F bond scission from hfac and tfac fragments attached to $\mathrm{ZnO}$ powder material is based on the previous studies of hfacH on copper surface, where the intact $-\mathrm{CF}_{3}$ fragment was initially removed in a thermal process and only then was further decomposition observed, leading to the surface fluorine contamination $[15,16]$. In other words, since the direct C-F dissociation in surface-bound species is very unlikely and since the C-C single bond is much more likely to dissociate within the $\mathrm{C}-\mathrm{CF}_{3}$ group compared to $\mathrm{C}-\mathrm{CH}_{3}$ group, the second step proposed to occur during the initial heating of surface bound $\mathrm{hfacH}$ and tfacH to about $400 \mathrm{~K}$ is the breaking of the $\mathrm{C}-\mathrm{C}$ bond in the $\mathrm{C}_{-} \mathrm{CF}_{3}$ entity observed experimentally. As shown in Figure 3, this step may lead either to the formation of delocalized structures (a) for tfac and (e) for hfac or ketene species (b) and (f), respectively. The metalacycle structures (a) and (e) in Figure 3 are stabilized by $\mathrm{Zn}-\mathrm{O}$ bonding, while less strained free-standing ketene-like structures (b) and (f) are stabilized by $\mathrm{C}=\mathrm{C}=\mathrm{O}$ formation. The specific channel may be influenced by the presence of electron-donating $\mathrm{CH}_{3}$ groups in organic species (a) and (b) vs. electron-withdrawing $\mathrm{CF}_{3}$ groups in species (e) and (f). From the 
thermodynamic parameters presented in Figure 3, the overall energy landscapes are similar for tfac and hfac, and the differences are clearly caused by the additional $-\mathrm{CF}_{3}$ group in hfac. Further heating of the proposed intermediate structures in all cases is expected to form additional ketene-like structures (described in detail in the next section), as also summarized in Figure 3.

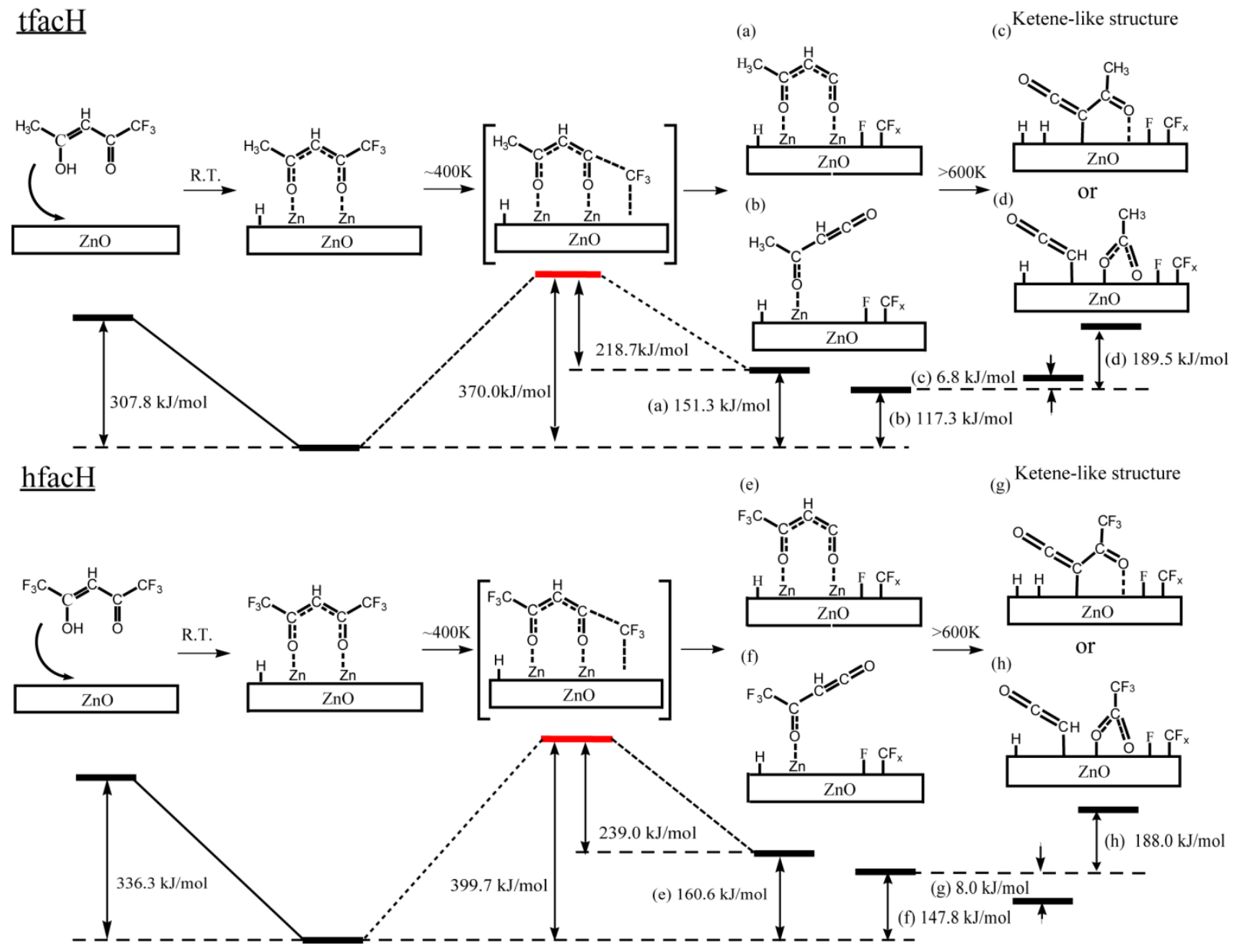

Figure 3. Proposed mechanisms of thermal transformation of $\mathrm{tfacH}$ and hfacH with corresponding energy changes. (a)-(h) show possible adsorbate structures observed at different temperatures during thermal transformation. 
According to a comparison summarized in Figure 3, the reactions expected to occur for tfacH and hfacH on $\mathrm{ZnO}$ are very similar but not identical. Despite the fact that similar diketonate species are formed in both cases initially and despite the similarity of proposed $\mathrm{C}-\mathrm{CF}_{3}$ scission by both tfac and hfac, the geometry, the energetics, and thus the relative concentration of surface species formed in these two processes are expected to be different. It should be pointed out that the barriers for breaking the $\mathrm{C}-\mathrm{C}$ bond in the $\mathrm{C}-\mathrm{CF}_{3}$ parts of the surface diketonates are very substantial in both cases; however, the exact numbers are certainly affected by specific surface arrangements, the presence of defects, and the electronic and steric influence of neighboring species. The most important piece of information in this comparison is the fact that the energetic requirements for $\mathrm{C}-\mathrm{CF}_{3}$ dissociation are different in these two seemingly very similar reactions.

3.3. Possible ketene-like structure formed on ZnO by tfac and hfac at elevated temperatures.

First, the possible formation of the ketene-like structures and spectroscopic confirmation of the corresponding reaction channels will be considered.

Girolami et al. [16] showed that adsorbed $\mathrm{Cu}(\mathrm{hfac})_{2}, \mathrm{Cu}(\mathrm{hfac}) \mathrm{VTMS}$ and hfacH 
would decompose on a copper surface and form ketenylidene species and $\mathrm{CF}_{3}$. On the other hand, a small amount of ketenylidene was also reported to be observed during decomposition of the acac group on the copper surface. A peak observed at $\sim 2038 \mathrm{~cm}^{-1}$ for decomposition of hfac species on $\mathrm{Cu}(100)$ was previously assigned to ketenylidene species. This stretching frequency is very similar to the absorption bands observed at elevated temperatures for tfac and hfac presented in Figure 2 above. Alternatively, similar vibrational features were reported for infrared investigation of propyne oxidation on $\mathrm{ZnO}$, where two peaks at $2046 \mathrm{~cm}^{-1}$ and $1982 \mathrm{~cm}^{-1}$ were assigned to be ketene-like species [44]. However, a study of ketene gas adsorbed on $\mathrm{ZnO}$ surface showed that surface acetate was the main observed species [45]. This comparison suggests that the structures formed on $\mathrm{ZnO}$ powder surface at elevated temperature by tfac and hfac are indeed ketene-like; however, they clearly represent not the ketene itself but rather a similar functionality stable at high temperature. Thus, two peaks observed at $\sim 2084 \mathrm{~cm}^{-1}$ and $\sim 1992 \mathrm{~cm}^{-1}$ for both tfac and hfac correspond to ketene-like structures produced at elevated temperatures.

As suggested by the mechanistic studies summarized in Figure 3, the formation of relatively stable ketene-like structures is possible for both tfac and hfac, especially at elevated temperatures. If the vibrational features corresponding to these species are compared to the experimental spectra, as shown in Figure 4, it can be concluded that even 
simple models used in the present study yield vibrational signatures fully consistent with the proposed mechanisms involving $\mathrm{C}-\mathrm{CF}_{3}$ scission.

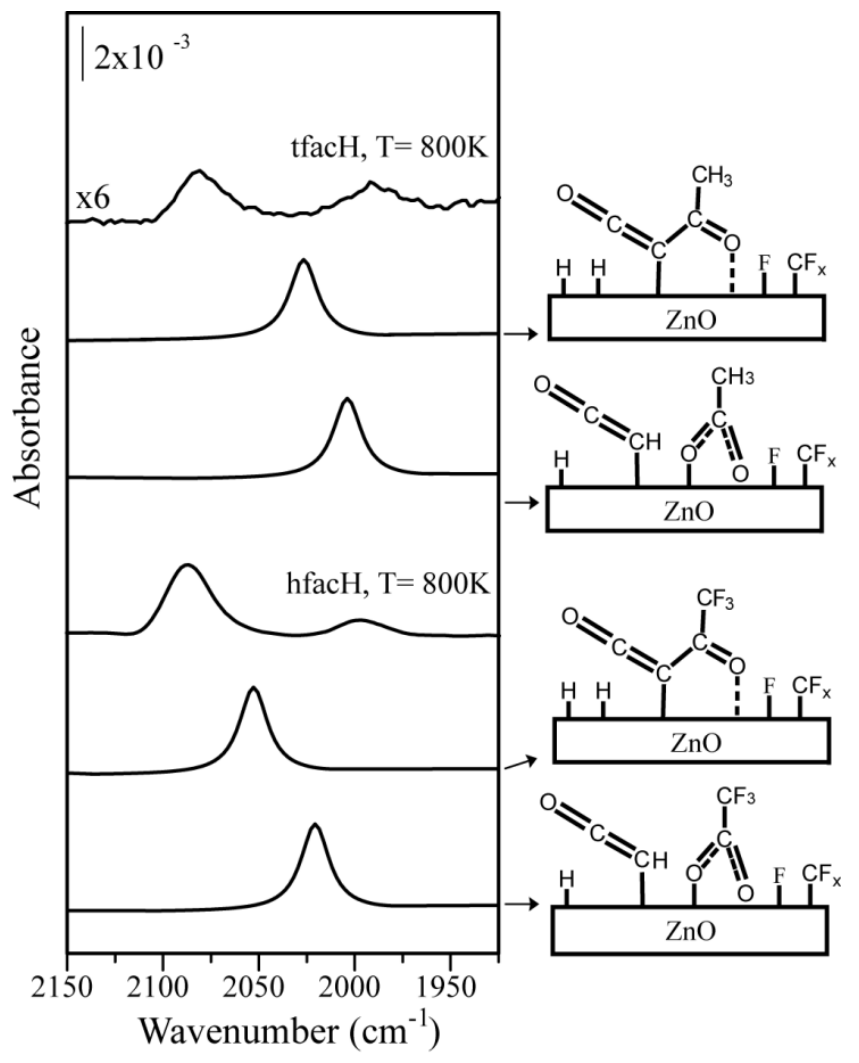

Figure 4. Infrared investigation of $\mathrm{tfacH}$ and hfacH adsorption on $\mathrm{ZnO}$ powder surface annealed to $800 \mathrm{~K}$ compared with the infrared spectra predicted by DFT for possible ketene-like structures (shown schematically on the right). The predicted computational frequencies are scaled by a factor of 0.97 .

The two frequencies assigned to the formation of ketene-like species are only observed for surface adsorbates with $\mathrm{C}_{-} \mathrm{CF}_{3}$ functionality but not for acacH. Thus, their presence is closely related to the type of mechanisms proposed in Figure 3. In other words, delocalized intermediates formed at lower temperatures (around $400 \mathrm{~K}$ ) lead to 
the formation of ketenes at higher temperatures $(600 \mathrm{~K})$ and these ketenes give rise to the observed vibrational features.

The detailed temperature-dependent evolution of surface ketene was studied with $50 \mathrm{~K}$ temperature increments and is presented in the supporting information section as Figure S3. Both ketene stretching vibrations are present between $600 \mathrm{~K}$ and $800 \mathrm{~K}$.

\subsection{Thermal decomposition of - $\mathrm{CF}_{3}$ in tfac and hfac ligands on $\mathrm{ZnO}$ powder}

The formation of ketenes at elevated temperature for tfac and hfac species occurs concurrently with the formation of surface-bound fluorine. It is important to address and understand this mechanistic step for both compounds. Figure 5 uses computational approach to compare the process of $\mathrm{C}-\mathrm{C}$ bond breaking for $\mathrm{C}-\mathrm{CF}_{3}$ entity in tfac and hfac on $\mathrm{ZnO}$. In general, both hfacH and tfacH show very similar trends in their behavior. Small differences in the structures of corresponding transition states and reaction products are consistent with the similar kinetic requirements shown in Figure 3 for tfac and hfac and with similar thermal behavior of the corresponding ketene-like structures. 


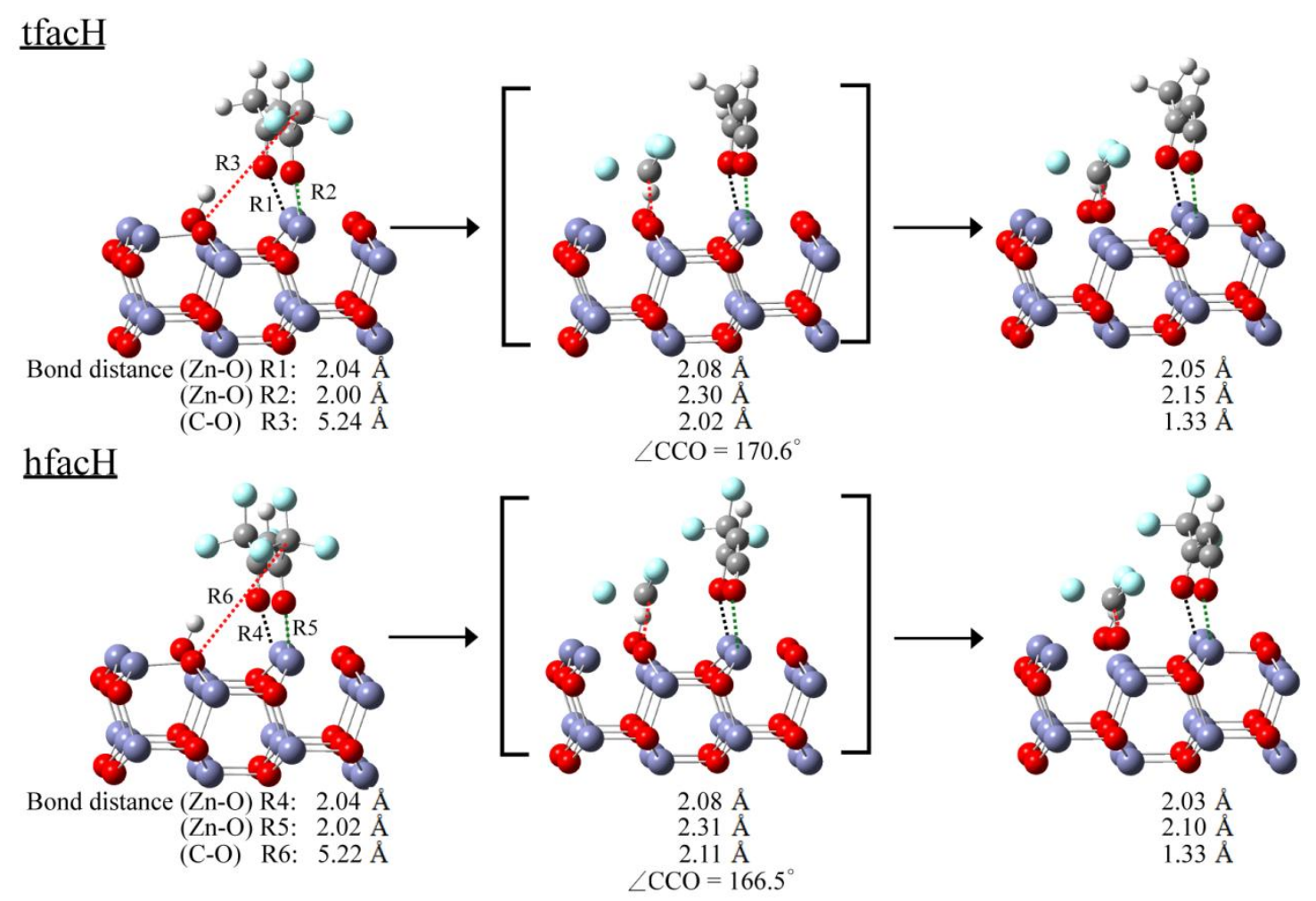

Figure 5. $\mathrm{C}_{-} \mathrm{CF}_{3}$ bond dissociation process for tfacH and hfacH on $\mathrm{ZnO}(10 \overline{1} 0)$. Representative $\mathrm{Zn}-\mathrm{O}$ and $\mathrm{C}-\mathrm{O}$ bond distances are shown below each structure.

Figure 3 also shows that as soon as $\mathrm{C}-\mathrm{CF}_{3}$ breaks up in both hfac and tfac ligands, this reaction is followed immediately by $\mathrm{C}-\mathrm{F}$ dissociation. A brief computational exploration of $\mathrm{CF}_{3}$ groups on zinc and oxygen sites of the $\mathrm{ZnO}$ surface presented in Figure S4 in the Supporting Information section shows a clearly elongated C-F bond (>1.50 $\AA$ ) parallel to the surface, compared with the approximately $1.40 \AA$ bonds unaffected by the surface presence in tfac or hfac. This observation is in agreement with the decomposition mechanisms described in Figure 3. Once the $\mathrm{C}-\mathrm{C}$ bond in the $\mathrm{C}-\mathrm{CF}_{3}$ species breaks, this process leads to the immediate formation of surface-bound $\mathrm{CF}_{2}$ and 
Zn-F.

\subsection{Thermal profile of chemical environment of fluorine for tfacH and hfacH adsorbed}

on ZnO powder determined by F1s XPS

Since the infrared spectroscopy studies described above suggested similarities in thermal transformations of $\mathrm{tfacH}$ and $\mathrm{hfacH}$ on the surface of $\mathrm{ZnO}$ powder, it is important to understand the chemical environment of fluorine in these compounds, and a very informative experimental approach to uncover it is XPS, specifically focused on $\mathrm{F} 1 \mathrm{~s}$ spectral region.

Figure 6 compares temperature-dependent behavior for $\mathrm{tfacH}$ and hfacH on the surface of $\mathrm{ZnO}$ powder followed by XPS. It is very clear that at least two types of features are observed for both compounds, with a single peak recorded for room-temperature adsorption around $688 \mathrm{eV}$ and another peak appearing in both cases following brief annealing to $600 \mathrm{~K}$ at approximately $684 \mathrm{eV}$. The peak at $688 \mathrm{eV}$ can be easily assigned to $\mathrm{C}-\mathrm{F}$ containing species. This assignment is based on the previous investigations of $\mathrm{Cu}(\mathrm{hfac})$ fragment adsorbed on $\mathrm{ZnO}$ powder surface [20]. It is fully consistent with other previously observed C-F containing species investigated with XPS [46], and it is also in a complete agreement with the DFT calculations for the species 
indicated in Figure 6 calibrated with a well-established procedure [38]. The peak emerging at elevated temperature at $684 \mathrm{eV}$ corresponds to the surface $\mathrm{Zn}-\mathrm{F}$ species. This assignment is made based on the previous investigations of the $\mathrm{ZnF}$-containing species by XPS [20] and is fully supported by the DFT calculations for the species shown in the figure. Thus, based on these two assignments, the chemical environment of fluorine upon adsorption of tfacH and hfacH on $\mathrm{ZnO}$ powder at room temperature is consistent with fluorine bound to carbon. Upon thermal annealing, the decomposition processes force fluorine atoms to migrate to the surface and attach to zinc atoms. This assignment of two binding energies allows for identification of the chemical environment of fluorine for these adsorption studies and also allows one to follow the decomposition processes as a function of temperature.

According to the data Figure 6, a small amount of $\mathrm{CF}_{3}$ fragments start to decompose around $400 \mathrm{~K}$ and surface concentration of $\mathrm{Zn}-\mathrm{F}$ species increases as a function of temperature, with the changes in peak areas clearly visible by $600 \mathrm{~K}$. This observation is in full agreement with the infrared studies reported above, where pronounced changes in the infrared spectra of tfacH and hfacH adsorbed on the surface of $\mathrm{ZnO}$ powder were recorded at $600 \mathrm{~K}$, while the initial changes started as low as $400 \mathrm{~K}$.

Another piece of quantitative information is useful in evaluating the mechanisms 
of surface decomposition of both species on $\mathrm{ZnO}$. If the relative intensities of the features at $688 \mathrm{eV}$ and at $684 \mathrm{eV}$ are compared for the two adsorbates at temperatures above 600 $\mathrm{K}$, following the completion of the decomposition process, it is clearly observed that for tfacH this ratio is approximately two to one. The same ratio for hfacH is at least twice as high. It is indeed possible that the decomposition process is rather complex and that some F-containing species start desorbing from the surface above $800 \mathrm{~K}$ (which is reflected in a smaller overall area of the observed features for hfacH annealed to $900 \mathrm{~K}$ ). However, this observation opens up a possibility to evaluate the thermal behavior of tfac and hfac on $\mathrm{ZnO}$ based simply on relative intensity of the two features. In fact, previous studies of fluorine-implanted $\mathrm{ZnO}$ material [47] suggest that even though the diffusion of fluorine in bulk $\mathrm{ZnO}$ starts as low as $400^{\circ} \mathrm{C}$, it results in subsurface depletion but not surface removal of fluorine from $\mathrm{ZnO}$ following higher temperature annealing. Thus, this analysis should be valid regardless of the specific species formed on the surface.

Tfac species has three fluorine atoms. According to the mechanism proposed in Figure 3, following the dissociation of a $\mathrm{C}-\mathrm{C}$ bond in the $\mathrm{C}_{-} \mathrm{CF}_{3}$ entity, formation of a surface-bound $\mathrm{CF}_{2}$ and $\mathrm{Zn}-\mathrm{F}$ is expected. Thus, the expected ratio of $\mathrm{C}-\mathrm{F}$ bonds observed at $688 \mathrm{eV}$ to $\mathrm{Zn}-\mathrm{F}$ bonds observed at $684 \mathrm{eV}$ is 2 to 1 . Hfac species possess 6 fluorine atoms in two $-\mathrm{CF}_{3}$ groups; however, only one of the two $-\mathrm{CF}_{3}$ groups is removed from 
hfac and dissociated into a surface-bound $\mathrm{CF}_{2}$ and $\mathrm{ZnF}$. In other words, in the case of hfacH, this ratio of the XPS features observed at $688 \mathrm{eV}$ and $684 \mathrm{eV}$ is expected to be 5 to 1. A slightly lower value observed for hfacH likely originates from other minor side reactions and also from inhomogeneity of the $\mathrm{ZnO}$ powder surface.

The fluorinated hydrocarbons, including $\mathrm{C}_{2} \mathrm{~F}_{6}$ and $\mathrm{C}_{2} \mathrm{~F}_{4}$ could potentially form and desorb at temperatures above room temperature contributing to the decrease in intensity of the observed $688 \mathrm{eV}$ peak in XPS; however, in the studies summarized in Figure 6, the overall $\mathrm{F} 1 s$ signal does not change substantially up to the annealing well above $800 \mathrm{~K}$; thus the comparison of the areas corresponding to features at $688 \mathrm{eV}$ and $684 \mathrm{eV}$ suggests that in the case of tfacH one out of every three fluorine atoms forms a $\mathrm{Zn}-\mathrm{F}$ bond, while the same process for hfacH yields one $\mathrm{Zn}-\mathrm{F}$ to at least four $\mathrm{C}-\mathrm{F}$ bonds. This implies that both tfacH and hfacH loose only one $\mathrm{CF}_{3}$ group initially in the course of thermal decomposition, leaving the other part of the ligand intact. This is fully consistent with the DFT investigation summarized in Figure 3. This observation also helps to rule out the possibility of a direct C-F dissociation instead of the $\mathrm{C}_{-} \mathrm{CF}_{3}$ scission followed by breaking a single $\mathrm{C}-\mathrm{F}$ bond of the surface $\mathrm{CF}_{3}$ group. If the direct $\mathrm{C}-\mathrm{F}$ dissociation were possible, it would be expected that larger number of $-\mathrm{CF}_{\mathrm{x}}$ entities would produce the correspondingly large number of $\mathrm{Zn}-\mathrm{F}$ species; however, the mechanistic (and thus 
geometric) limitations yield the specific $\mathrm{CF}_{2}$ to $\mathrm{Zn}-\mathrm{F}$ ratios discussed above.

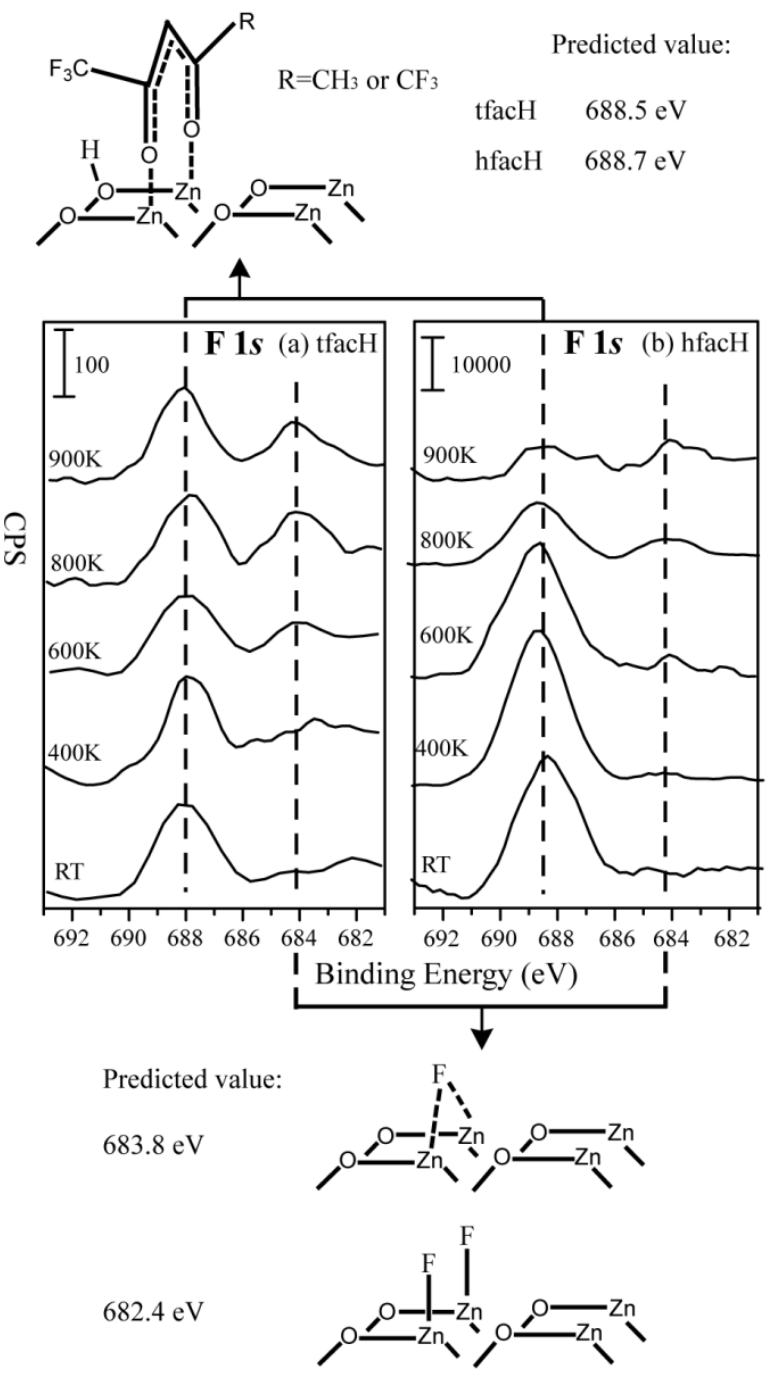

Figure 6. XPS spectra of $\mathrm{F} 1 s$ region for (a) tfacH and (b) hfacH adsorbed on $\mathrm{ZnO}$ powder surface. Possible corresponding F-containing species obtained with DFT analysis for $\mathrm{ZnO}(10 \overline{1} 0)$ surface are shown along with corresponding predicted XPS binding energies.

The $\mathrm{C}$ 1s and $\mathrm{O}$ 1s spectra presented as Figure S5 in the Supporting Information section are a little bit more difficult to follow compared to those of the $\mathrm{F}$ 1s region 
(because of the possibility of surface contamination during the transfer to the XPS chamber); however, they are fully consistent with the proposed mechanisms. O $1 \mathrm{~s}$ is indeed rather difficult to use for specific assignments because of the large signal from the oxygen in $\mathrm{ZnO}$ and small differences in the core level shifts for - $\mathrm{O}-\mathrm{H}$ as opposed to, for example, -O-C species. The C 1s spectra as a function of temperature clearly show the change of $-\mathrm{CF}_{3}$ to $-\mathrm{CF}_{2}$ upon annealing, again fully consistent with the $\mathrm{F} 1 \mathrm{~s}$ behavior described above.

\section{Summary.}

Based on the comparison of the reactions of three $\beta$-diketones on $\mathrm{ZnO}$ powder surface, a set of specific requirements to the stability and transformations of these compounds can be obtained:

1) The initial step in the reactions of all the $\beta$-diketones studied is the $\mathrm{O}-\mathrm{H}$ dissociation of the enol form of each compound.

2) Surface diketonates formed as a result of this initial dissociation are stable at room temperature.

3) The weakest bond that leads to further thermal decomposition of all the diketonates studied is the $\mathrm{C}-\mathrm{C}$ within the $\mathrm{C}-\mathrm{CF}_{3}$ entity of the fluorinated derivatives. The absence 
of this functionality (in acac) leads to higher thermal stability compared to the other diketonates studied.

4) Despite substantial similarities in the decomposition process for tfacH and hfacH, subtle differences in energetics, likely influenced by the electron-donating nature of the $\mathrm{CH}_{3}$ group in tfac compared to the electron-withdrawing $\mathrm{CF}_{3}$ in hfac, have to be taken into account while covering thermal decomposition of these two different compounds.

5) Only the presence of the $\mathrm{C}-\mathrm{CF}_{3}$ entity in tfac and hfac species allows for the formation of surface ketenes at elevated temperatures.

\section{Conclusions.}

The results provided in this work show a nearly complete picture of thermal transformation of $\beta$-diketones on $\mathrm{ZnO}$ powder. Even though these thermally induced chemical processes are fairly complicated, our studies focus on understanding the differences between $\mathrm{CH}_{3}$-substituted and $\mathrm{CF}_{3}$-substituted $\beta$-diketones and the role of the ketene-like structures formed at elevated temperatures in the overall decomposition process. It has been confirmed that the selective $\mathrm{C}-\mathrm{C}$ bond dissociation in the $\mathrm{C}-\mathrm{CF}_{3}$ functionality is a key step that determines the mechanistic differences among the three 
$\beta$-diketones investigated. Based on the experimental evidence and with the help of DFT calculations, a plausible set of mechanisms has been designed that explains these differences; however, further improvements and selectivity studies are needed to fully uncover the origins of these chemical transformations. The details of this study are important in both designing catalytic transformations of ketones and fluorinated compounds on $\mathrm{ZnO}$ and on metallic catalysts supported on $\mathrm{ZnO}$ and in designing deposition schemes involving $\beta$-diketonates to produce the required supported catalysts.

Supporting Information Available: Table of IR frequencies with approximate assignments based on the computational studies; comparison of the $\mathrm{O}-\mathrm{H}$ stretching region investigated by infrared spectroscopy for water, acacH, tfacH and hfacH on $\mathrm{ZnO}$ powder at room temperature, summary of the computational studies of acacH dissociation on $\mathrm{ZnO}(10 \overline{1} 0)$, temperature-dependent infrared studies of hfacH on $\mathrm{ZnO}$ within the $600 \mathrm{~K}$ to $900 \mathrm{~K}$ temperature range, comparison of $\mathrm{CF}_{3}$ species on surface $\mathrm{Zn}$ and $\mathrm{O}$ sites, summary of C 1s and O 1s XPS spectra. This material is available free of charge via the Internet at http://xxx.xxx.xxx. 


\section{Acknowledgments}

Acknowledgment is made to the donors of the Petroleum Research Fund, administered by the American Chemical Society, for partial support of this research. This work was also supported by the National Science Foundation (CHE 1057374). The Surface Analysis Facility (Department of Chemistry and Biochemistry, University of Delaware) work was supported by the Delaware COBRE program, with a grant from the National Institute of General Medical Sciences - NIGMS (1 P30 GM110758-01) from the National Institutes of Health. The authors would like to thank Mrs. Rachel Pupillo for help with collecting XPS spectra at the Surface Analysis Facility. Professor Robert Opila and his student Mr. Kevin Jones are acknowledged for their help with selected XPS investigations.

\section{References}

[1] R. Ciganda, M.A. Garralda, L. Ibarlucea, E. Pinilla, M.R. Torres, Dalton Trans., 39 (2010) 7226-7229.

[2] M. Okumura, K. Tanaka, A. Ueda, M. Haruta, Solid State Ionics, 95 (1997) 143-149.

[3] A. Jain, T.T. Kodas, M.J. Hampden-Smith, Thin Solid Films, 269 (1995) 51-56.

[4] Y.Y. Maruo, J. Nakamura, M. Uchiyama, Talanta, 74 (2008) 1141-1147. 
[5] S.F. Tayyari, F. Milani-Nejad, H. Rahemi, Spectrochim. Acta A, 58 (2002) 1669-1679.

[6] M. Zahedi-Tabrizi, F. Tayyari, Z. Moosavi-Tekyeh, A. Jalali, S.F. Tayyari, Spectrochim. Acta A, 65 (2006) 387-396.

[7] M.J. Hampden-Smith, T.T. Kodas, Chem. Vap. Deposition, 1 (1995) 8-23.

[8] T.T. Kodas, M.J. Hampden-Smith, The Chemistry of Metal CVD, VCH, Weinheim (1994).

[9] M. Hosseini-Sarvari, Curr. Org. Synth., 10 (2013) 697-723.

[10] M.A. Barteau, Chem. Rev., 96 (1996) 1413-1430.

[11] J. Gao, A.V. Teplyakov, J. Catal., 319 (2014) 136-141.

[12] C. Hariharan, Appl. Catal., A, 304 (2006) 55-61.

[13] L. Ravichandran, K. Selvam, M. Swaminathan, Aust. J. Chem., 60 (2007) 951-956.

[14] M.D. Driessen, T.M. Miller, V.H. Grassian, J. Mol. Catal. A: Chem., 131 (1998) $149-156$.

[15] V.M. Donnelly, M.E. Gross, J. Vac. Sci. Technol. A, 11 (1993) 66-77.

[16] G.S. Girolami, P.M. Jeffries, L.H. Dubois, J. Am. Chem. Soc., 115 (1993) 1015-1024.

[17] K.A. Perrine, A.V. Teplyakov, Langmuir, 26 (2010) 12648-12658.

[18] D.G. Rayner, J.S. Mulley, R.A. Bennett, J. Vac. Sci. Technol. A, 31 (2013) 01A121. 
[19] D.N. Goldstein, S.M. George, Thin Solid Films, 519 (2011) 5339-5347.

[20] H. Kung, A.V. Teplyakov, J. Phys. Chem. C., 118 (2013) 1990-1998.

[21] C. Wöll, Prog. Surf. Sci., 82 (2007) 55-120.

[22] U. Diebold, S.-C. Li, M. Schmid, Annu. Rev. Phys. Chem., 61 (2010) 129-148.

[23] J.M. Vohs, M.A. Barteau, Surf. Sci., 221 (1989) 590-608.

[24] J.A. Wingrave, A.V. Teplyakov, J. Vac. Sci. Technol. A, 21 (2003) 1800-1801.

[25] J. Gao, A.V. Teplyakov, J. Catal., 300 (2013) 163-173.

[26] A.D. Becke, J. Chem. Phys., 98 (1993) 1372-1377.

[27] A.D. Becke, J. Chem. Phys., 98 (1993) 5648-5652.

[28] A. Wander, N.M. Harrison, Surf. Sci., 457 (2000) 342-346.

[29] P.J. Hay, W.R. Wadt, J. Chem. Phys., 82 (1985) 270-283.

[30] P.J. Hay, W.R. Wadt, J. Chem. Phys., 82 (1985) 299-310.

[31] W.R. Wadt, P.J. Hay, J. Chem. Phys., 82 (1985) 284-298.

[32] M. J. Frisch, G. W. Trucks, H. B. Schlegel, G. E. Scuseria, M. A. Robb, J. R.

Cheeseman, G. Scalmani, V. Barone, B. Mennucci, G. A. Petersson, H. Nakatsuji, M.

Caricato, X. Li, H. P. Hratchian, A. F. Izmaylov, J. Bloino, G. Zheng, J. L.

Sonnenberg, M. Hada, M. Ehara, K. Toyota, R. Fukuda, J. Hasegawa, M. Ishida, T.

Nakajima, Y. Honda, O. Kitao, H. Nakai, T. Vreven, J. A. Montgomery, Jr., J. E. 
Peralta, F. Ogliaro, M. Bearpark, J. J. Heyd, E. Brothers, K. N. Kudin, V. N. Staroverov, R. Kobayashi, J. Normand, K. Raghavachari, A. Rendell, J. C. Burant, S. S. Iyengar, J. Tomasi, M. Cossi, N. Rega, J. M. Millam, M. Klene, J. E. Knox, J. B. Cross, V. Bakken, C. Adamo, J. Jaramillo, R. Gomperts, R. E. Stratmann, O. Yazyev, A. J. Austin, R. Cammi, C. Pomelli, J. W. Ochterski, R. L. Martin, K. Morokuma, V. G. Zakrzewski, G. A. Voth, P. Salvador, J. J. Dannenberg, S. Dapprich, A. D. Daniels, Ö. Farkas, J. B. Foresman, J. V. Ortiz, J. Cioslowski, and D. J. Fox, Gaussian 09, Revision D.01, Gaussian, Inc., Wallingford CT, 2009.

[33] J. Gao, A.V. Teplyakov, Catal. Today, 238 (2014) 111-117.

[34] K. Hsuan, T. Andrew, J. Phys.: Condens. Matter, 27 (2015) 054007.

[35] J.-M. Lin, A. Teplyakov, Theor. Chem. Acc., 132 (2013) 1-14.

[36] C. Peng, H. Bernhard Schlegel, Isr. J. Chem., 33 (1993) 449-454.

[37] C. Peng, P.Y. Ayala, H.B. Schlegel, M.J. Frisch, J. Comput. Chem., 17 (1996) 49-56.

[38] T.R. Leftwich, A.V. Teplyakov, J. Electron. Spectrosc. Relat. Phenom., 175 (2009) $31-40$.

[39] T.L. Bahers, T. Pauporté, F.d.r. Labat, G.g. Lefèvre, I. Ciofini, Langmuir, 27 (2011) 3442-3450.

[40] H. Noei, H. Qiu, Y. Wang, E. Loffler, C. Woll, M. Muhler, Phys. Chem. Chem. Phys., 
10 (2008) 7092-7097.

[41] A.V. Teplyakov, B.E. Bent, J. Eng Jr, J.G. Chen, Surf. Sci., 399 (1998) 342-350.

[42] H. Noei, C. Wöll, M. Muhler, Y. Wang, Appl. Catal. A, 391 (2011) 31-35.

[43] Y.-R. Luo, Bond Dissociation Energies, http://staff.ustc.edu.cn/ luo971/2010-91-CRC-BDEs-Tables.pdf.

[44] T. Nakajima, T. Sonoda, H. Miyata, Y. Kubokawa, J. Chem. Soc. Faraday Trans. , 78 (1982) 555-565.

[45] K. Vikulov, D. Scarano, A. Zecchina, S. Coluccia, J. Chem. Soc., Faraday Trans., 89 (1993) 1127-1129.

[46] W. Lin, B.C. Wiegand, R.G. Nuzzo, G.S. Girolami, J. Am. Chem. Soc., 118 (1996) 5977-5987.

[47] A.Y. Azarov, B.G. Svensson, A.Y. Kuznetsov, Appl. Phys. Lett., 101 (2012) 222109-222109-4. 


\section{TOC Image}

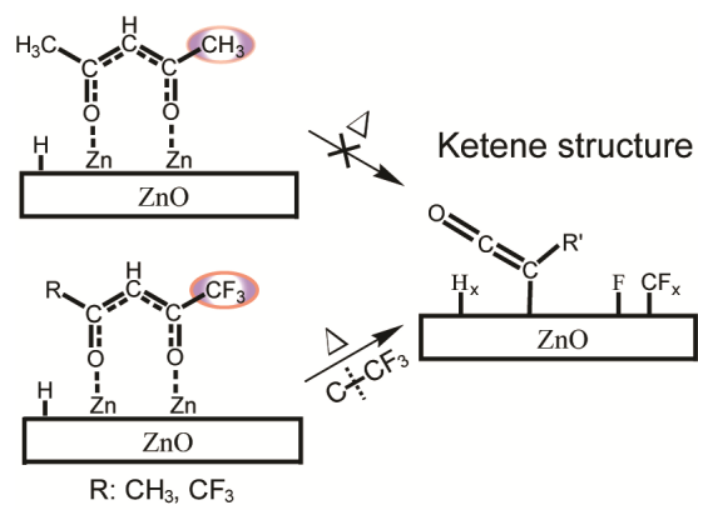

